The Labore Journal of Economics

$10: 1$ (Summer 2005) pp. 123-139

\title{
Arbitrage Pricing Theory: Evidence From An Emerging Stock Market
}

\section{Javed Iqbal $^{*}$ and Aziz Haider ${ }^{* *}$}

The development of financial equilibrium asset pricing models has been the most important area of research in modern financial theory. These models are extensively tested for developed markets. This paper examines the validity of the Arbitrage Pricing Theory (APT) model on returns from 24 actively trading stocks in Karachi Stock Exchange using monthly data from January 1997 to December 2003. Explanatory factor analysis approach indicates two factors governing stock return. Pre-specified macro economic approach identifies these two factors as the anticipated and unanticipated inflation and market index and dividend yield. Some evidence of instability is found. The overall finding of two significant priced factors at least for a sub period supports APT for an emerging capital market.

\section{Introduction}

The applications of financial equilibrium models have been very intensively investigated. These applications are used for various purposes such as predicting common stock systematic risk and defining the cost of capital. The traditional equilibrium model, the capital asset pricing model (CAPM) of Sharp (1964), Linter (1965) and Mossin (1966) assume that stock returns are generated by a one-factor model, where the factor represents the market portfolio of all risky assets. Empirical tests of the CAPM have produced mixed results. The critical point in the estimation of the CAPM is the difficulty of measuring the true market portfolio. Due to the severe problems in the testing the CAPM (Copeland and Weston, 1988) a number of the other models have been proposed.

Arbitrage pricing theory, developed by Ross (1976) proposes that there are several sources of risk in the economy that cannot be eliminated by diversification. These sources of risk can be thought of as related to

\footnotetext{
* PhD student at Monash University, Department of Econometrics \& Business Statistics Australia. E-mail: javed_uniku@yahoo.com

** MSc student (Final) Department of Statistics, University of Karachi. E-mail: aziz_hashmi82@yahoo.com
} 
economy wide factors such as inflation and changes in aggregate output. Instead of calculating a single beta, like the CAPM, arbitrage pricing theory calculates many betas by estimating the sensitivity of an asset's return to changes in each factor.

The arbitrage pricing theory assumes that a security return is a linear function, not only of one, but also a set of common factors. The APT thus indicates that the risk premium for an asset is related to the risk premium for each factor and that as the asset's sensitivity to each factor increases, its risk premium will increase as well. The APT predicted that the prices of all risky assets in the economy conformed to the condition of no arbitrage. No arbitrage mean that an individual holding a well-diversified portfolio could not earn any additional return merely by changing the weights of the assets included in the portfolio, holding both systematic and unsystematic risk constant. The APT states that there is a set of underlying sources that influence all stocks returns. The stock return is a linear function of a certain number; say $\mathrm{k}$, of economic factors, while these factors are unobservable and not meaningful.

According to Chen et al. (1986), these risk factors arise from changes in some fundamental economic and financial variables such as interest rates, inflation, real business activity, a market index, investor confidence etc.

The APT thus starts with the assumption that returns on any stocks, $R_{i t}$, are generated by a k-factors model of the following for

$$
R_{i t}=E\left(R_{i}\right)+b_{i 1} F_{1}+b_{i 2} F_{2}+\ldots+b_{i k} F_{k}+\varepsilon_{i}
$$

Where $E\left(R_{i}\right), \mathrm{i}=1,2,3 \ldots \mathrm{n}$, is the expected return of the stock i. $F_{j}$ $(\mathrm{j}=1,2,3 \ldots \mathrm{k}$,$) are unobserved economic factors. b_{i j}$ is the sensitivity of the security $\mathbf{i}$ to the economic factors $\mathfrak{j}$ and $\varepsilon_{i}$ are the unique risks of the stocks (uncontrolled factor) i-e a random error term with mean equal to zero and variance equal to $\sigma_{e i}^{2}$.

Ross (1976) showed that if the number of stocks is sufficiently large, the following linear risk-return relationship holds.

$$
E\left(R_{i}\right)=\lambda_{\circ}+\lambda_{1} b_{i 1}+\lambda_{2} b_{i 2}+\ldots+\lambda_{k} b_{i k} \quad \ldots
$$

Where $\lambda_{\circ}$ is a constant risk less rate of return (the common return on all zero-beta stocks), and $\lambda_{j}, j=1,2, \ldots, k$ represents, in equilibrium, the risk 
premium for the jth factor. The mean zero random common factors can be thought of as representing unanticipated changes in fundamental economywide variables. The sensitivity coefficients measure the magnitude and direction of the reaction in asset returns.

In order to test the APT empirically, there are two main approaches. First, one can simultaneously estimate the asset sensitivities and unknown factors by exploratory factor analysis on stock returns. In that case a theory does not predict the exact content or even the number of relevant factors. Alternatively, we could try to specify prior general factors that explain pricing in the stock market. Such macroeconomic variables could be those affecting either future cash flows on companies or future risk-adjusted discount rates. It is generally accepted that the trend of pre-specifying factors seems to be a promising avenue of research in the search for meaningful factor structure.

The factor analysis-based empirical tests of the APT on US data have produced relatively mixed results. In their seminal paper, Roll and Ross (1980) tested the APT for the period 1962-72. They used daily data for individual equities listed on the New York Stock Exchange. They concluded that at least three and probably four priced factors were found in the return generating process.

Chen (1983) discovered that the APT seems to outperform the traditional CAPM when evaluated by explanatory power on stock returns. He investigated stocks using daily return data during the 1963-1978 period from the New York Stock Exchange. He compared the empirical performance of the APT with that of the CAPM.

More studies have found a number of critical issues when testing the theory. For example, it has been found that the number of factors seems to increase when the number of investigated securities increases. There is a paucity of research evaluating the validity of the APT in non-US stock markets. The sparse European results of the APT include these reported in Diacgiannis (1986), Abeysekera and Mahajan (1988), Rubio (1988), Ostermark (1989), Yli-Olli and Virtanen (1989), and Yli-Olli et al. (1990). Concerning the Scandinavian results, Ostermark (1989) reported APTdominance on Finnish as well as Swedish data. Yli-Olli et al. (1990) found three stable common factors across these two neighbouring countries, for the period 1977-1986, using monthly data. They used the principal component analysis to get the factor loadings, then cross-sectional OLS regressions were applied for the three factor solutions to test how many factors were priced in the two countries. 
An alternative to the traditional approach is to specify a priori, on the basis of the theory, the general factors that explain pricing in the stock market. In this case the common factors are first measured using pre-specified macroeconomic variables, and asset sensitivities to these factors are estimated using time series regressions. In their seminal paper, Chen et al. (1986) found that the spread between long-term and short-term interest rates, expected and unexpected inflation, industrial production and spread between high and lowgrade bonds are priced in the generating process of stock returns in the US stock market. These state variables have also been found to be important in a number of other studies on US data such as Chen (1989).

Martikainen et al. (1991) tested APT for the Finish Stock Market using monthly data. They used two different approaches: an exploratory factor analysis and a pre-specified macroeconomic factor approach. They tested how many factors there were that affected finish stocks in the two time periods 1977-81 and 1982-86. In the first step of the test they used principal components analysis and varimax rotation to get the factor loadings. Then, OLS regressions were made where factor loadings were independent variables and the average return on stock was the dependent variable. The purpose was to find how many factors that were priced in the market. In the second step of the test they used 11 pre-specified macroeconomic factors to test the APT model. They used different stock market indices, price indices, interest rates and other national economic variables such as the GNP and money supply. They could find only one priced factor for the first subperiod. In the second subperiod all of the factors become priced. This was an encouraging result that supported the theory that the equilibrium stock returns were generated by an economic factor model.

Loflund (1992) found that international factors such as unanticipated changes in real exchange rates, inflation and unanticipated changes in future foreign economic activity or export demand should be important. National factors such as unexpected inflation, unanticipated changes in the shortterm interest rate, the term structure of interest rates and unexpected changes in domestic real production should be important.

Booth et al. (1993) tested the APT for US, Finnish and Swedish stock returns during the 1977-86 period, using monthly data. They tested the intracountry stability of the factor patterns over time and across different samples. They investigated the cross-sectional similarities of the factor patterns of twelve 30-stock samples. They used transformation analysis to test the stability. The empirical evidence indicated that two stable common factors in different samples could be found. An interesting observation was that the factors were very often produced in different order in different samples. Another important finding was that there existed two common factors across 
the first US sample and Finnish and Swedish samples. Thus, the two common factors obtained have been international by nature. The results implied that for Finland the APT performed relatively poorly and for US and Swedish data one to two priced factors were identified.

For developing capital markets in general and Pakistani markets in particular empirical evidence on equilibrium models are few. Khilji (1993) and Hussain and Uppal (1998) investigated the distributional characteristics of stock return in the Karachi Stock Exchange concluding that the return behavior cannot be adequately modeled by a normal distribution. Hussain (2000) found no evidence of the day of the week anomaly and concluded that for the period January 1989 to December 1993 the absence of this predictability pattern implied efficiency of the market. Ahmad and Zaman (2000) using sectoral monthly data from July 1992 to March 1997 found that some of the CAPM implications are valid in the Karachi Stock Market. They found evidence in favor of positive expected return for investors but speculative bubbles were also indicated. Khilji (1994) found that the majority of return series are characterized by non-linear dependence. Ahmad and Rosser (1995) used an ARCH-in-Mean specification to study risk return relationship using sectoral indices. Attaullah (2001) tested APT in the Karachi Stock Exchange using 70 randomly selected stocks employing monthly data from April 1993 to December 1998. Out of 11 macroeconomic factors he found unexpected inflation, exchange rate, trade balance and world oil prices were sources of systematic risk. He used Iterative Non Linear Seemingly Unrelated Regressions technique. The present study provides another more recent evidence from monthly data from January 1997 to December 2003. With a relatively greater sample this study employs two different factor analysis techniques and stability analysis is also performed. Moreover macroeconomic variables used are also greater in number and regional market indices are also included.

The remainder of this paper is organized as follows. Section II, the data used in this research effort is introduced. The empirical part of the study is divided into two sections. Section III includes testing the APT using traditional exploratory factor analysis approach. In Section IV macroeconomic factors are identified using 16 pre-specified macroeconomic variables by reducing the dimensionality of these variables using factor analysis. The APT is also tested using these macroeconomic factors. Section V concludes.

\section{The Data}

The data consist of 24 actively traded stocks from the Karachi Stock Exchange and the general market index (KSE-100), covering the period from January 1997 to December 2003. Data on individual stocks regarding 
closing prices was obtained from the Karachi Stock Exchange. These 24 stocks are the most active stocks with approximately $80 \%$ weight of aggregate market capitalization of KSE 100 index companies. We have collected the monthly data. In order to analyze the stability of the factors in the APT, the period is divided into two subperiods

The first subperiod is from January 1997 to December 1999; the second is from January 2000 to December 2003. One reason for breaking the sample is stability testing of our results. Moreover the second period is more volatile. In this period KSE attained its highest level of index value and market capitalization. It is claimed to be the best performing capital market in the world. Therefore we need a large sample for reliable estimates, while the first period January 97 to December 99 is relatively smooth. The break up of the sample can also be seen as pre-Musharaf government and the current government. President Musharaf Government's intended or unintended economic, financial and foreign policies due to the 9/11 event have brought drastic changes in the economic horizon. So it will also be tested whether stock return behavior has changed in the two subperiods.

The returns have been measured using the first difference of monthly logarithmic price indices. There are 16 macroeconomic variables, including inflation measured by Consumer Price Index and Wholesale Price Index, a measure of real economic activity. Ideally GDP should be used for this purpose but the monthly data on GDP are not yet available for Pakistan therefore manufacturing production index has been used to capture real economic activity. Interest rate measured by 90 day T-bill of SBP, Money market rate, a long-term interest rate yield on 10-year Pakistan Investment Bond are also investigated in the analysis. When selecting the macroeconomic variables, they have been chosen using the criterion that they should affect the rate of return or future cash flow expectations of the firm share. All the variables are studied using the first differences of the logarithmic forms of indices.

Inflation has been proxied by two indices measuring the wholesale prices and the consumer prices. These variable are included in the study since the classical Fisherian theory implies that the common stocks should serve as an effective inflation hedge during expected inflation (see Mishkin, 1997). It is generally observed that stock returns are negatively related to expected inflation, unexpected inflation and change in expected inflation in several countries (Asprem, 1989; Wasserfallen, 1989). When expected inflation rises, interest rates will rise. Fama (1981), Geska and Roll (1983), Ram and Spencer (1983), Stulz (1986), and Kaul (1987) all attempt to explain the negative association between stock returns and inflation; and Fama and Gibbons (1982) 
attempt to explain the negative association between inflation and real interest rates.

Interest rates are among the most closely watched variables in the economy. Their movements are reported almost daily by the news media. They directly affect our everyday lives and have important consequences for the health of the economy. The higher the interest rate, the higher the discount factor, and lower the stock prices. Martikainen et al (1991) used this variable in testing the APT model. The stock returns and production growth, as outlined in Barro (1990) and Fama (1990), may be affected by interest rates. Recently the boom in the Pakistani Stock Market (KSE 100 index in all time highest in the recent past) is partly due to the fact that interest rates in defense certificates and other interest-bearing instrument have declined. Therefore investors are now coming to the stock market, as a result demand for stock market securities is rising which increase stock prices.

The regional market may have an effect on returns in the Karachi Stock Exchange. In empirical studies many authors have used regional market return as an independent variable, for example, for the case of the Finland capital market (Helsinki Stock Exchange) Martikainen et al (1991) have used the Stockholm Index.

Emerging Stock Market Factbook (1999) indicates that for the Pakistani capital market the highest correlation of returns are with the Indian capital market (0.40) and Malaysian capital market (0.36). Therefore in our analysis we have used the Bombay Stock Index (BSE-30) and Kuala Lumpur Composite Index (KLSE).

The U.S. stock market was by far the largest and most influential capital market in the world. Therefore we have used Standard and Poor 500 index. S \& P index reflects the worldwide expectations for all firms. The S \& $P$ index has been selected since it is expected that the Pakistani stock returns follow the global cash-flow expectations of firms. Rozeff (1984), Shiller (1984) and Campbell and Shiller (1988) present evidence that dividend yields forecast stock returns, Fama and French (1989) suggest that dividend yields can explain cyclical variation in expected returns. Chen et al. (1985) find that changes in aggregate production, inflation, and short-term interest rates can explain the equilibrium pricing of equities, and Chen (1991) shows that the cyclical behaviour of T-bill rates captures the cyclical variation in equity risk premiums. 
The money supply has typically been seen as a leading indicator, and it is usually assumed that money supply and demand influence equity prices (Fama, 1981; Geske and Roll, 1983; Kaul, 1987). The rise in money supply can be expected to raise the stock prices (Martikainen et al., 1991). Kaul (1990) also indicates significant association between monetary rule and the relationship between stock returns and inflationary expectations. Monetary policy influences stock returns by increasing future cash flows or by decreasing the discount factors at which those cash flows are capitalized (Binswanger, 2000).

\section{Exploratory Factor Analysis Approach}

Our exploratory factor analysis approach is based on intuition, which was presented by Chen et al. (1986) and which has been applied further by several researchers. First, the factor scores and factor loadings from the return series were estimated separately for the two subperiods and the whole period. The estimation of factors was based on the principal component method. Second, an orthogonal varimax rotation was applied. In the following table, factors appear in decreasing order of variance explained by the factors.

\section{Table-1: Cumulative Proportions Of The Total Variance Explained By Principal Components}

\begin{tabular}{|c|c|c|c|c|c|c|c|c|c|}
\hline Period & Fact 1 & Fact 2 & Fact 3 & Fact 4 & Fact 5 & Fact 6 & Fact 7 & Fact 8 & Fact 9 \\
\cline { 1 - 9 } Jan-97--Dec-03 & 0.456 & 0.526 & 0.583 & 0.631 & 0.675 & 0.713 & 0.749 & 0.782 & 0.812 \\
\cline { 1 - 2 } & 0.478 & 0.557 & 0.622 & 0.677 & 0.726 & 0.773 & 0.811 & 0.846 & 0.875 \\
Jan-00--Dec-03 & 0.467 & 0.543 & 0.604 & 0.659 & 0.71 & 0.749 & 0.787 & 0.818 & 0.845 \\
\hline
\end{tabular}

The cumulative proportions of the total variance explained by the estimated factors are presented in Table 1 . The results indicate that the figures are quite stable over the two subperiods. We concentrate on nine factors solution. This selection is based on the criteria of more than $80 \%$ variance explained by the factors extracted. Using this criteria the Pre-specified macroeconomic factors also support the existence of nine factors. The results of the other estimated factor solutions are available from the authors on request.

Thus, the following nine-factor models were estimated for the stocks to obtain asset sensitivities and unknown factors in the APT.

$$
R_{i t}-\mu_{i}=b_{i 1} F_{1 t}+b_{i 2} F_{2 t}+\ldots .+b_{i 9} F_{9 t}+e_{i t}
$$


Where $R_{i t}, i=1,2, \ldots, 24$, is the return of the stock $\mathrm{i}$ at month $\mathrm{t}, \mu_{i}$ represent the mean return of the stock $i, F_{1 t}, F_{2 t}, \ldots, F_{9 t}$ are the estimated unknown common factors (factor scores), $b_{i 1}, b_{i 2}, \ldots, b_{i 9}$ are the asset sensitivities (factor loadings) of the security $i$ to the nine unknown factors, and $e_{i t}$ are the unsystematic return components of the stocks.

To test the linear risk-return relation implied by the APT, Table- 2 presents OLS regressions where the estimated factor loadings are used as independent variables, and the average returns of securities as dependent variables.

Table-2: Regression Analysis Estimates For The Exploratory Factor Analysis-Unrotated 9 Factors In The Model

\begin{tabular}{|l|c|c|c|c|c|c|c|c|c|c|c|}
\hline Period & Const & Fact 1 & Fact 2 & Fact 3 & Fact 4 & Fact 5 & Fact 6 & Fact 7 & Fact 8 & Fact 9 & $\mathbf{R}^{2}$-adj \\
\hline Jan-97- & - & -0.007 & 0.0133 & -0.0045 & 0.0030 & 0.0252 & 0.0112 & -0.0095 & -0.005 & 0.0197 & $41.20 \%$ \\
Dec-03 & 0.0008 & & & & 3 & & & & & & \\
T-value & -0.09 & -0.55 & 1.45 & -0.77 & 0.38 & $3.57^{* * *}$ & 1.42 & -1.31 & -0.62 & $2.12^{*}$ & \\
\hline $\begin{array}{l}\text { Jan-97-- } \\
\text { Dec-99 } \\
\text { T-value }\end{array}$ & 0.0197 & 0.02 & -0.014 & -0.007 & 0.0055 & 0.0109 & 0.0126 & 0.0094 & -0.012 & -0.006 & $16.10 \%$ \\
\hline $\begin{array}{l}\text { Jan-00- } \\
\text { Dec-03 }\end{array}$ & 0.0155 & 1.27 & -1.26 & -0.7 & 0.78 & 1.46 & 0.93 & 0.91 & -1.06 & -0.65 & \\
T-value & $1.91 *$ & 1.35 & -0.002 & -0.0093 & 0.008 & 0.0124 & -0.01 & -0.007 & -0.017 & 0.0053 & $42.00 \%$ \\
\hline
\end{tabular}

Dependent variable: average monthly return for security; independent variables: factor loadings.

* Significant at 0.10 leve1.

** Significant at 0.05 level.

*** Significant at 0.01 leve1.

The results indicate that in the whole sample period we can find two priced factors according to this exploratory factor analysis approach; in the first subperiod none of the factors seems to be priced, and in the second subperiod we can find only one priced factor at the $5 \%$ significance level. The number of priced factors seems to be very low and the results of this approach indicate substantial instability of the explanatory power of the APT. This instability may be due to a number of reasons as explained in section II.

\section{Pre-Specified Macroeconomic Factors Approach}


Table-3 presents the principal components analysis on the 16 prespecified macroeconomic variables- the rotated solution. According to $80 \%$ of the variance explained criteria, the original variables were converted to 9 orthogonal time series. There are two reasons for the conversion. Firstly this eliminates all problems with multi-colinearity and secondly it reduces the dimensionality of the original variables and makes it easier to work with time-series.

The factors in Table-3 appear in decreasing order of variance explained by the factors, i.e. according to the eigenvalues of the factors. The figures in the table are factor loading. Factor 1 indicates the real economic activity, which are positively correlated. Factor 2 and factor 3 represented the anticipated change and unanticipated change of inflation, which are also positively correlated. Factor 4 represented stock index factor namely Bombay Stock Exchange (BSE) and Karachi Stock Exchange (KSE) and dividend yield with factor loadings $0.760,0.509$ and -0.834 respectively. Factor 5 and factor 8 indicate clearly interest rate factor. Factor 6 indicates the stock index factor Standard and Poor's index (S\&P) and BSE showing negative correlation that is -0.906 and -0.487 respectively. Factor 7 represented the money supply factor. Exchange rates are represented by factor 9 having factor loading 0.976 .

Tabel-3. Factor Pattern of the Macroeconomic Variables January-97 to December-03

\begin{tabular}{lccccccccc}
\hline Variable & F1 & F2 & F3 & F4 & F5 & F6 & F7 & F8 & F9 \\
\hline Dmanu & 0.89 & -0.07 & -0.08 & -0.01 & 0.13 & 0.02 & -0.20 & 0.04 & -0.06 \\
ddManu & 0.87 & 0.03 & -0.14 & -0.10 & 0.00 & -0.09 & -0.11 & -0.24 & 0.12 \\
DKSE & -0.11 & 0.02 & -0.08 & 0.76 & 0.07 & -0.15 & -0.03 & -0.19 & 0.07 \\
dS\&P & 0.03 & -0.03 & 0.04 & 0.04 & -0.01 & -0.91 & 0.01 & 0.15 & -0.07 \\
DBSE & 0.12 & -0.17 & -0.07 & 0.51 & -0.06 & -0.49 & -0.40 & -0.09 & -0.02 \\
DKLSE & 0.02 & -0.07 & -0.15 & 0.20 & -0.01 & -0.03 & -0.06 & 0.02 & -0.06 \\
dCPI-95 & -0.02 & 0.17 & 0.91 & -0.05 & -0.15 & 0.03 & 0.03 & 0.10 & -0.08 \\
DdCPI & -0.19 & 0.11 & 0.90 & -0.01 & 0.09 & -0.06 & -0.11 & -0.01 & 0.01 \\
dWPI-95 & 0.10 & 0.89 & 0.17 & 0.08 & -0.07 & 0.07 & 0.05 & 0.05 & -0.03 \\
ddWPI & -0.15 & 0.91 & 0.09 & 0.06 & -0.01 & 0.00 & -0.10 & -0.01 & 0.03 \\
dExch.R & 0.04 & 0.00 & -0.06 & 0.01 & -0.14 & 0.08 & 0.01 & 0.04 & 0.98 \\
dT-bil1 & -0.01 & -0.01 & -0.02 & 0.01 & -0.82 & 0.18 & -0.14 & 0.30 & 0.10 \\
dGovtB & -0.13 & 0.11 & 0.08 & -0.08 & -0.82 & -0.22 & 0.13 & -0.21 & 0.08 \\
\hline
\end{tabular}




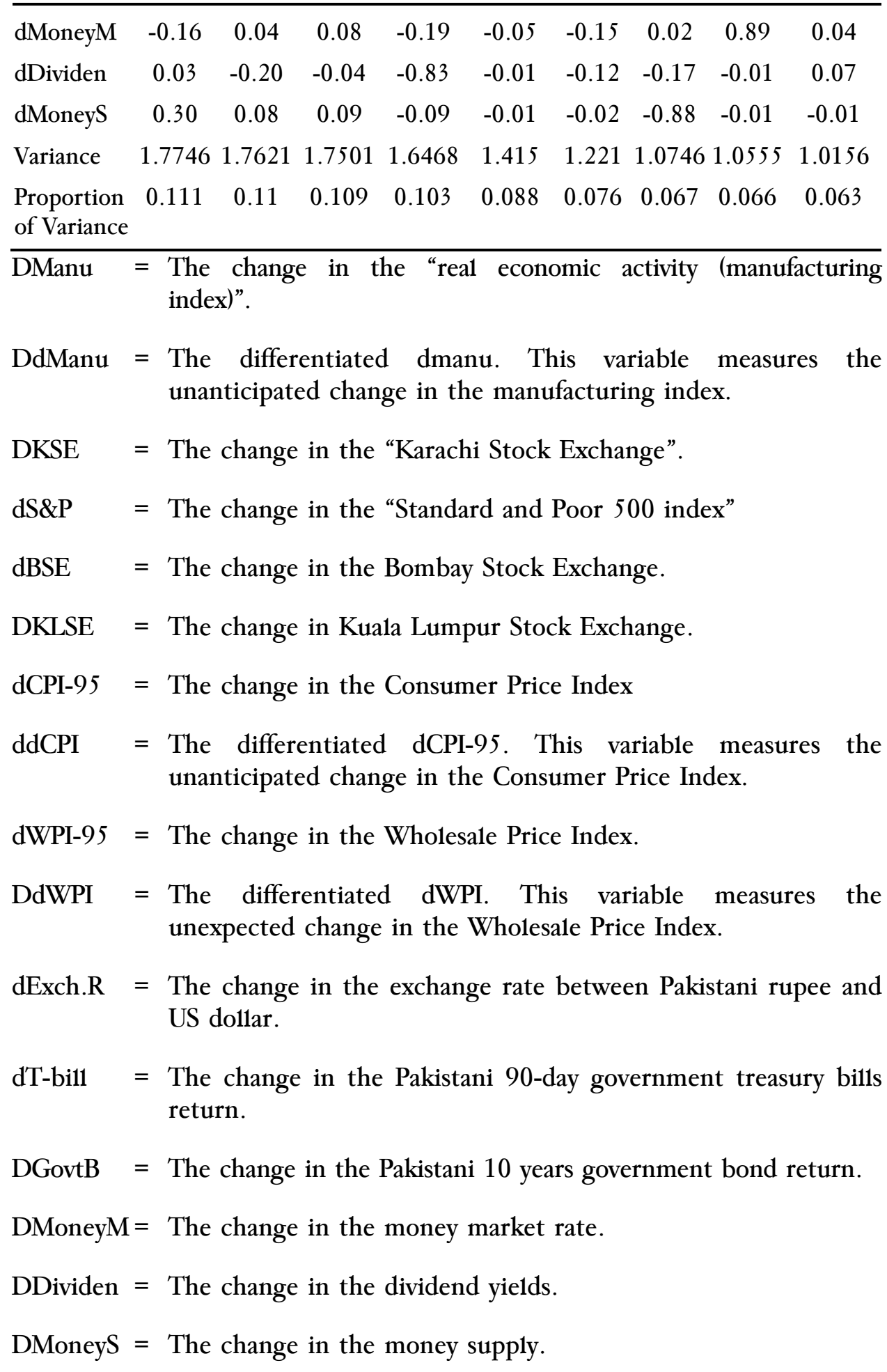


The data have been obtained from various issues of International Financial Statistics and Monthly Bulletin of State Bank of Pakistan. Stock index data Bombay Stock Exchange and Karachi Stock Exchange data have been obtained from www.scsecurities.com

To test the APT using pre-specified macro-economic factors, the following time-series regressions were first estimated for the stocks to obtain asset sensitivities and unknown factors in the APT.

$$
R_{i t}=\alpha_{i}+b_{1} F_{1}+b_{2} F_{2}+\ldots .+b_{k} F_{k}+e_{i t}
$$

Where $R_{i t}$ is the return of the stock $\mathrm{i}$ at month $\mathrm{t}, \alpha_{i}$ is the intercept term of the stock $\mathrm{i}, F_{j}(j=1,2, \ldots, k)$ are in the above factor analysis estimated macroeconomic factors (factor scores), $b_{i j}(j=1,2, \ldots, k)$ are the sensitivities of the return of the security $\mathrm{i}$ and $e_{i t}$ are the unsystematic return components of the stocks. In this OLS factor scores are used as independent variables and stocks return for each stock as dependent variable. From this we estimate factor sensitivity (factor loading).

Using these factor sensitivities as independent variable and stock average returns as dependent variable, the following regression was run

$$
\bar{R}_{i}=L_{\circ}+L_{1} b_{1}+L_{2} b_{2}+\ldots+L_{K} b_{K}
$$

This estimated risk premium L's and tested which factors were priced. The results of this regression are reported in Table- 4 .

\section{Table-4: Regression Analysis Estimates For The Pre-Specified Factors}

\begin{tabular}{|c|c|c|c|c|c|c|c|c|c|c|c|}
\hline Period & Const & Fact 1 & Fact 2 & Fact 3 & Fact 4 & Fact 5 & Fact 6 & Fact 7 & Fact 8 & Fact 9 & $\mathbf{R}^{2}$-adj \\
\hline \multirow{2}{*}{$\begin{array}{l}\text { Jan-97- } \\
\text { Dec-03 } \\
\text { T-value }\end{array}$} & 0.0171 & 0.0423 & -0.0725 & 0.4283 & -0.2313 & 0.1842 & 0.031 & 0.0589 & 0.0650 & 0.2164 & \multirow{2}{*}{$\begin{array}{c}39.30 \\
\%\end{array}$} \\
\hline & $3.8^{* * * *}$ & 0.31 & -0.574 & $2.38^{* *}$ & $-3.7 * * *$ & 0.96 & 0.24 & 0.48 & 0.48 & 1.61 & \\
\hline \multirow{2}{*}{$\begin{array}{l}\text { Jan-97- } \\
\text { Dec-99 } \\
\text { T-value }\end{array}$} & 0.0177 & 0.0453 & -0.1689 & 0.1366 & 0.2598 & -0.0186 & 0.030 & 0.0441 & -0.0095 & -0.0152 & \multirow{2}{*}{$\begin{array}{c}48.20 \\
\%\end{array}$} \\
\hline & $5.04 * * *$ & 0.4600 & -1.1100 & $3.9 * * *$ & $\begin{array}{c}2.3300^{*} \\
*\end{array}$ & -0.1500 & $\begin{array}{c}0.230 \\
0\end{array}$ & 0.4500 & -0.100( & -0.1800 & \\
\hline
\end{tabular}
Approach:- Rotated 


\begin{tabular}{|c|c|c|c|c|c|c|c|c|c|}
\hline \multirow{2}{*}{\begin{tabular}{|l} 
Jan-00- \\
Dec-03 \\
T-value
\end{tabular}} & $\begin{array}{lll}0.0134 & -0.1575 & 0.1429\end{array}$ & $\begin{array}{c}- \\
0.0358\end{array}$ & -0.2275 & 0.1082 & $\begin{array}{c}0.059 \\
0\end{array}$ & & & 0.0782 & \multirow[t]{2}{*}{$7.40 \%$} \\
\hline & $1.7000-1.47000 .8300$ & $\begin{array}{c}- \\
0.1900\end{array}$ & -1.0000 & 0.7800 & $\begin{array}{c}0.220 \\
0\end{array}$ & 0.9600 & 0.3100 & 0.3700 & \\
\hline
\end{tabular}

Dependent variable:- average monthly return for security.

Independent variables:- sensitivities of asset returns to changes in macroeconomic factors.

* Significant at 0.10 levels.

** Significant at 0.05 levels.

*** Significant at 0.01 levels.

The results imply that we can find two priced factor in the whole sample period when factor 3 and 4 become priced. The first sample period also shows the same result but this time the only change is the significance level is reversed. We know from the analysis in the preceding step that the third factor is the anticipated and unanticipated inflation and the fourth factor is the stock market index and dividend yield. The second sample period shows no priced factor. As value of the intercept is significant, it is likely that there are other factors which are not included in our study, that affect stock returns and also are priced. Again, quite a high level of instability is found in the results.

\section{Conclusions}

The results of two different testing methods for the Arbitrage Pricing Theory (APT) are nearly the same because in the whole sample period two priced factors are found. This is an encouraging result, which supports the theory. But the number of priced factors seems to be very low and the results of both approaches indicate substantial instability of the explanatory power of the APT. Explanatory factor analysis approach indicates two factors governing stock return. Pre-specified macro economic approach identifies these two factors as the unanticipated and anticipated inflation, market index and dividend yield. The former factor was also identified by Attaullah (2001). Some evidence of instability is found. In the second subperiod namely January 2000 to December 2003 that is more volatile, the APT based on exploratory factor analysis on stock returns performs relatively well. In the first subperiod extending from January 1997 to December 1999 the APT based on pre-specified macroeconomic variables is supported. 


\section{References}

Abeysekera, S. P. and Mahajan, A. 1988, A test of the APT using UK stocks, Journal of Business Finance and Accounting, 14, 377-391.

Ahmad, E. and Rosser, B.J. 1995, Non-linear speculative bubbles in the Pakistan stock markets Pakistan Development Review, 34 (1), $25-41$.

Ahmad, E. and Zaman, B.U. 2000, Risk, uncertainty and return at Karachi Stock Exchange, The Labore Journal of Economics, 5(2) 107-126.

Asprm, M. 1989, Stock prices, asset portfolios and macroeconomic variables in ten European countries, Journal of Banking and Finance, 13, 589-612.

Attaullah, A. 2001, Macroeconomic variables as common pervasive risk factors and empirical content of the Arbitrage Pricing Theory in Pakistan, The Lahore Journal of Economics, 6 (1) 55-77.

Barro, R. 1990, The stock market and investment, Review of Financial Studies, 3, 115-31.

Binswanger, M. 2000, Stock returns and real activity: is there still a connection?, Applied Financial Economics, 10, 379-387.

Booth et a1. 1993, On the Existence of Common Factors in the Arbitrage Pricing Model: Internaltional Evidence From US and Scandinavian Stock Markets, Applied Financial Economics, 3.

Campbell, J.Y. and Shiller, R. 1988, The dividend-price ratio and expectations of future dividends and discount factors, Review of Financial Studies, 1, 195-228.

Chen, N. 1991, Financial investment opportunities and macroeconomy, Journal of Finance, 46, 529-54.

Chen, N., Chan, K. and Hsieh, D. 1985, An exploratory investigation of the firm size effect, Journal of Business, 56, 383-403.

Chen, N.F. 1983, Some Empirical Tests of the Theory of Arbitrage Pricing, Journal of Finance, Vo1 XXXVIII, No 5. 
Chen, N-F. 1989, Financial investment opportunities and the real economy. Paper presented to the $16^{\text {th }}$ Meeting of the European Finance Association.

Chen, N-F., Ro11, R. and Ross, S.A. 1986, Economic forces and the stock market, Journal of Business, 59, 383-403.

Copeland, T. E. and Weston, J. F. 1988, Financial theory and corporate policy, Addison-Wesley, Reading, Ma.

Diacogiannis, G. P. 1986, Arbitrage Pricing Mode1: a critical examination of its empirical applicability for the London Stock Exchange, Journal of Business Finance and Accounting, 12, 489-504.

Emerging Stock Market Factbook 1999, International Finance Corporation, Washington.

Fama, E. F. 1981, Stock returns, real activity, inflation, and money, American Economic Review, 71, 545-65.

Fama, E. F. 1990, Stock returns, expected returns, and real activity, Journal of Finance, 45, 1089-180.

Fama, E. F. and French, K. R. 1989, Business conditions and expected returns on stocks and bonds, Journal of Financial Economics, 25, 23-49.

Fama, E. F. and Michad, R. Gibbons 1982, Infaltion, real returns and capital investment, Journal of Monetary Economics, 9, 297-323

Geske, R. and Rol1, R. 1983, The fiscal and monetary linkage between stock returns and inflation, Journal of Finance, 38, 1-38.

Hussain, F. 2000, The day of the week effect in the Pakistan equity market: An investigation, The Lahore Journal of Economics, 5(1), 93-98

Hussain, F. and Uppa1, J. 1998, Distribution of stock returns in an emerging market: The Pakistani market, Pakistan Economic and Social Review, 36 (1), 47-72.

Kaul, G. 1987, Stock returns and inflation. The role of the monetary sector, Journal of Financial Economics, 18, 253-276. 
Kau1, G. 1990, Monetary regimes and the relation between stock returns and inflationary expectations, Journal of Financial and Quantitative Analysis, 25, 307-321.

Khilji, N. M. 1993, The behaviour of stock return in an emerging market: A case study of Pakistan. Pakistan Development Review, 32 (4), 593-604.

Khilji, N. M. 1994, Nonlinear dynamics and chaos: Application to financial market in Pakistan. Pakistan Development Review, 33 (4), 14171429.

Lintner, J. 1965, The Valuation of Risk Assets and the Selection of Risky Investments in Stock Portfolios and Capital Budgets, Rev. Econ. Statistics, 47(1).

Loflund 1992, Arbitrage Pricing Theory in a Small Open Economy-Empirical Evidence from the Swedish Stock Market, Forskningsrapport, Svenska Handelshogskolan, Helsingfors.

Martikainen, T., Yli-O1li, P. and Gunasekaran, A. 1991, Incremental significance of pre-specified macroeconomic factors in testing the arbitrage pricing theory: empirical evidence with Finnish data, Applied Financial Economics, 1, 139-147.

Mishkin, F. S. 1997, The Economics of Money, Banking, and Financial Market, Addison Wesley Longman Inc.

Mossin, J. 1966, Equilibrium in a Capital Asset Market, Econometrica, 34,5.

Ostermark. 1989, Arbitrage Pricing Models for Two Scandinavian Stock Markets, Omega International Journal of Management Science.

Ram, R. and David E. S. 1983, Stock returns, real activity, inflation, and money: comment, American Economic Review, 73, 463-470.

Rol1, R. and Ross, S. A. 1980, An empirical investigation of the Arbitrage Pricing Theory, Journal of Finance, 35, 1073-1103.

Ross, S. A. 1976, The Arbitrage Pricing Theory of capital asset pricing, Journal of Economic Theory, 13, 341-360.

Rozeff, M. 1984, Dividend yields are equity risk premiums, Journal of Portfolio Management, 68-75. 
Rubio, G. 1988, Further international evidence on asset pricing: the case of Spanish capital market, Journal of Banking and Finance, 12, 221-242.

Sharpe, W. F. 1964, Capital Asset Prices: A theory of market equilibrium under conditions of risk, Journal of Finance 19(5).

Shiller, R. J. 1984, Stock prices and social dynamics, Brookings Papers on Economic Activity, 2, 457-510.

Stulz,R. M. 1986, Asset pricing and expected inflation, Journal of Finance, 41, 209-223.

Wasserfallen, W. 1989, Macroeconomic news and the stock market. Evidence from Europe, Journal of Banking and Finance, 13, 613-626.

Yli-Olli, P. and Virtanen, I. 1989, Arbitrage Pricing Theory and its empirical applicability for the Helsinki Stock Exchange, European Institute for Advanced Studies in Management, Working Paper 89-07.

Yli-Olli, P., Virtanen I. and Martikainen, T. 1990, Common factors in the Arbitrage Pricing Model in two Scandinavian countries, OMEGA International Journal of Management Science, 18, 615-624. 